\title{
Early differentiation and evolution of magmatic iron meteorite parent bodies inferred from $\mathrm{Mn}-\mathrm{Cr}$ chronometry.
}

\author{
ARYAVART ANAND ${ }^{1}$, JONAS PAPE ${ }^{2}$, MARTIN WILLE ${ }^{3}$, \\ KLAUS MEZGER $^{3}$ AND BEDA HOFMANN ${ }^{4}$ \\ ${ }^{1}$ Institute of Geological Sciences \\ ${ }^{2}$ University of Münster \\ ${ }^{3}$ University of Bern \\ ${ }^{4}$ Naturhistorisches Museum Bern \\ Presenting Author: aryavart.anand@geo.unibe.ch
}

Members of magmatic iron meteorite groups are thought to sample the cores of distinct parent bodies that experienced largescale chemical fractionation, most notably metal-silicate separation. The timing of metal core formation in the magmatic iron meteorite parent bodies provides a key time marker for the evolution of early formed planetesimals. The timing and duration of such early solar system processes, including accretion, differentiation and subsequent cooling, can be investigated using the short-lived ${ }^{53} \mathrm{Mn}-{ }^{53} \mathrm{Cr}\left(\mathrm{t}_{1 / 2} \approx 3.7 \mathrm{Ma}\right)$ chronometer.

Chromite and daubréelite are the two main carrier phases of $\mathrm{Cr}$ in magmatic iron meteorites. Both minerals have low $\mathrm{Mn} / \mathrm{Cr}$ ratios $(\approx 0.01)$ and thus, preserve the $\mathrm{Cr}$ isotope composition of their growth environment at the time of isotopic closure, while the in-growth of radiogenic ${ }^{53} \mathrm{Cr}$ from in-situ decay of ${ }^{53} \mathrm{Mn}$ is negligible. The $\mathrm{Cr}$ isotope ratios do not need any correction for cosmic ray exposure due to the low $\mathrm{Fe} / \mathrm{Cr}$ of the samples. Model ages for chromite and daubréelite in magmatic iron meteorites can be obtained by comparing their $\mathrm{Cr}$-isotope composition with the Cr-isotope evolution of the chondritic reservoir, using the known ${ }^{1}$ abundances of ${ }^{53} \mathrm{Mn}$ and ${ }^{53} \mathrm{Cr}$ at the beginning of the solar system or any point in time thereafter and an estimate ${ }^{1}$ for the $\mathrm{Mn} / \mathrm{Cr}$ in the relevant reservoir.

The mean $\mathrm{Mn}-\mathrm{Cr}$ core formation age for IIAB, IIIAB and IVA meteorites is $\sim 1 \mathrm{Myr}$ younger than their mean Hf-W core formation age $^{2}$. A better fit can be obtained by adjusting the model parameters for $\mathrm{Mn}-\mathrm{Cr}$ model age determination. Uncertainties on the ${ }^{53} \mathrm{Mn}$ decay constant and initial solar system ${ }^{53} \mathrm{Mn} /{ }^{55} \mathrm{Mn}$ result in only minor uncertainties in the model ages of generally $<0.02$ Myrs and hence can be ignored. However, determining the model ages using solar system initial $\varepsilon^{53} \mathrm{Cr}=$ -0.29 , which is within its reported uncertainty $\left(\varepsilon^{53} \mathrm{Cr}=\right.$ $-0.23 \pm 0.09)^{1}$ results in a perfect fit with the mean ${ }^{182} \mathrm{Hf}-{ }^{182} \mathrm{~W}$ model ages for magmatic iron meteorite groups. Consequently, $\varepsilon^{53} \mathrm{Cr}=-0.29 \pm 0.04$ is proposed as a better estimate of the solar system initial $\varepsilon^{53} \mathrm{Cr}$.

REFERENCES

[1] Trinquier, A. et al. (2008) GCA, 72 (20), 5146-5163.

[2] Kruijer, T.S. et al. (2014) Science, 344(6188), 1150-1154. 